\title{
Effects of early tooth loss on the hippocampus in senescence-accelerated mice
}

\author{
Yoko Hioki*1, Mitsuo Iinuma*1, Chika Kurata*1, Yukiko Ichihashi*1, \\ Yasuo Tamura*1 and Kin-ya Kubo*2 \\ *1 Department of Pediatric Dentistry, Division of Oral Structure, Function and Development, \\ *2 Department of Oral Anatomy, Division of Oral Structure, Function and Development, \\ Asahi University School of Dentistry \\ 1851-1 Hozumi, Mizuho, Gifu 501-0296, JAPAN
}

\begin{abstract}
We evaluated whether long-term tooth loss induces functional and morphologic changes in the hippocampus in senescence-accelerated mice (SAMP8) maintained until old age after tooth extraction shortly after tooth eruption. First, to examine whether early tooth loss acts as a stressor, plasma concentration was measured as an index of stress. Plasma corticosterone concentration was significantly higher in old or mature mice with tooth extraction than in the age-matched controls. Plasma corticosterone concentration did not differ between the young tooth extraction and their age-matched control groups. Next, hippocampal function was assessed by evaluating spatial memory performance in the Morris water maze. In the Morris water maze learning and memory trials was significantly slower in the mature or old tooth extraction groups compared with the age-matched controls. There was no significant difference, however, between the young tooth extraction and control groups. Finally, hippocampal neuronal morphology was assessed by counting Nisslstained cells. The number of hippocampal neurons was significantly reduced in the CA3 region in the mature and old tooth extraction groups compared with their age-matched controls, but there was no significant difference in the CA1-region or dentate gyrus between the mature or old tooth extraction groups and their age-matched controls. In young mice, there was no significant difference in the number of neurons in $\mathrm{CA} 1, \mathrm{CA} 3$, or dentate gyrus region between the tooth extraction and control groups. The findings indicated that tooth extraction after tooth eruption enhances the effects of aging on the hippocampus in mice.
\end{abstract}

\author{
Key words \\ Corticosterone, \\ Early tooth loss, \\ Hippocampus, \\ Learning ability, \\ Senescence-accelerated mice \\ (SAMP8)
}

\section{Introduction}

Tooth loss impairs mastication and is related to Alzheimer's disease ${ }^{1)}$ and dementia ${ }^{2}$, as well as to changes in oral structures such as the mandible and temporomandibular joint ${ }^{3}$. Further, tooth extraction in young mice accelerates aging and decreases life $\operatorname{span}^{4,5}$. Tooth extraction in aged mice increase plasma corticosterone concentrations ${ }^{6}$. As the plasma glucocorticoid concentration increases when animals are

Received on March 16, 2009

Accepted on June 2, 2009 exposed to chronic stress ${ }^{7)}$, tooth loss is thought to act as a chronic stressor. Chronic stress impairs spatial memory ${ }^{8)}$, and leads to a decrease in neurons ${ }^{9)}$, an increase in glial fibrillary acidic protein-positive cells $^{10)}$, a decrease in acetylcholine release in the higher centers of the brain ${ }^{11)}$, particularly the hippocampus, and a decrease in Fos-positive cells in areas of the hippocampus considered important for learning ${ }^{12)}$. In all of these studies, however, the teeth were extracted at young, mature, and old ages and soon induces functional and morphologic changes. In the present study, we extracted the teeth soon after eruption, maintained the animals until maturation 
and old age, and evaluated whether the long-term absence of teeth induces functional and morphologic changes in the hippocampus. First, to examine whether early tooth loss acts as a stressor, we measured the plasma corticosterone concentration as an index of stress.

We then tested the mice in the Morris water maze to evaluate the functional effects of early tooth loss on spatial memory. Finally, we examined the effect of early tooth loss on the number of hippocampal neurons.

\section{Materials and Methods}

Male senescence-accelerated mice (SAMP8; $n=60)$ were used in the study. The strain was kindly donated by the Institute of Frontier Medical Sciences, Kyoto University. We bred brother-sister in the animal facility of the Central Research Division at the School of Dentistry, Asahi University. The SAMP8 mouse has an average life span of 12 months (about half life span of normal mice) and begins to show deficits in learning and memory and aging at 5 months. The characteristics of this strain were described in detail by Takeda et al. ${ }^{13,14)}$. The animals were bred and maintained under conventional conditions; housed in groups of 5 in plastic cages $(175 \mathrm{~W}$ $\times 245 \mathrm{D} \times 125 \mathrm{H} \mathrm{mm})$ under temperature $\left(23 \pm 1^{\circ} \mathrm{C}\right)$, humidity $(55 \pm 2 \%)$, and light $(12 \mathrm{~h}$; light period, 6:00-18:00; dark period, 18:00-6:00) controlled conditions; and water was available ad libitum. This experiment was conducted according to the Animal Experiment Guidelines established by Asahi University.

\section{Tooth extraction procedure}

The mice were separated from the dams 4 weeks after birth. At 1 month after birth, 30 mice were anesthetized with pentobarbital $\left(\mathrm{Nembutal}^{\circledR}\right.$, Dainihonseiyaku Co., Ltd., Osaka, $30 \mathrm{mg} / \mathrm{kg}$ intraperitoneal injection), fixed in the supine position, and the upper molar teeth on both sides were extracted using an excavator as carefully as possible to minimize bleeding (extraction group). The other 30 mice underwent the same anesthesia without surgery and served as controls (control group). Following surgery solid food $\left(\mathrm{CE}-2^{\circledR}\right.$, Japan Clea Co., Ltd.) was given and the mice were maintained for 1 week (young group), 4 months (mature group), and 8 months (old group).

\section{General conditions}

Body weight and food intake of the young, mature, and old mice was measured for 9 days, 4 months, and 8 months, respectively, after surgery.

\section{Corticosterone concentrations}

At 1 week (young group), 4 months (mature group), and 8 months (old group) after surgery, plasma corticosterone concentrations were assayed in the control and molarless mice ( $\mathrm{n}=5$ for each group). Corticosterone concentrations have a circadian variation, peaking at the beginning of the dark period, when activity is generally greatest, and reaching the lowest levels near the end of the dark period or at the beginning of the light period, when the mice are least active ${ }^{15)}$. Therefore at 20:00, the beginning of the dark period, blood was sampled in $2.0 \mathrm{ml}$ microcentrifuge tubes containing no anticoagulant. The blood samples were immediately centrifuged at $3,500 \times \mathrm{G}$ for $10 \mathrm{~min}$ at $4^{\circ} \mathrm{C}$, and the serum was stored at $-80^{\circ} \mathrm{C}$ until the assay was performed. Corticosterone was measured by radioimmunoassay by SRL Biochemistry Lab (Tokyo, Japan).

\section{Morris water maze test}

The Morris water maze test is a sensitive behavioral assay for hippocampal abnormalities ${ }^{16,17}$. At 1 week (young group), 4 months (mature group), and 8 months (old group) after surgery, Morris water maze test was performed as described previously ${ }^{8-10)}$. Briefly, a stainless steel tank $(90 \mathrm{~cm}$ in diameter, $30 \mathrm{~cm}$ deep) was filled with water (approximately $28^{\circ} \mathrm{C}$ ) to a height of $22 \mathrm{~cm}$ and the water surface was covered with floating polystyrene foam granules (approximately $2 \mathrm{~mm}$ in diameter). A platform $(12 \mathrm{~cm}$ in diameter) was submerged $1 \mathrm{~cm}$ under the water surface and located at a constant position near the center of one of the four quadrants of the pool. Training consisted of 28 trials over 7 days (4 trials per day, approximately 5-min intertrial interval). For each trial, the mice were placed into the water from one of four points at the perimeter of the tank. The sequence of the starting positions was randomized daily. A CCD video camera linked to a computer system (Move-tr/2D, Library Co., Ltd., Tokyo, Japan) was used to measure the latency of each mouse to reach the platform.

\section{Hippocampal neuron number}

After the Morris water maze 5 mice of each 

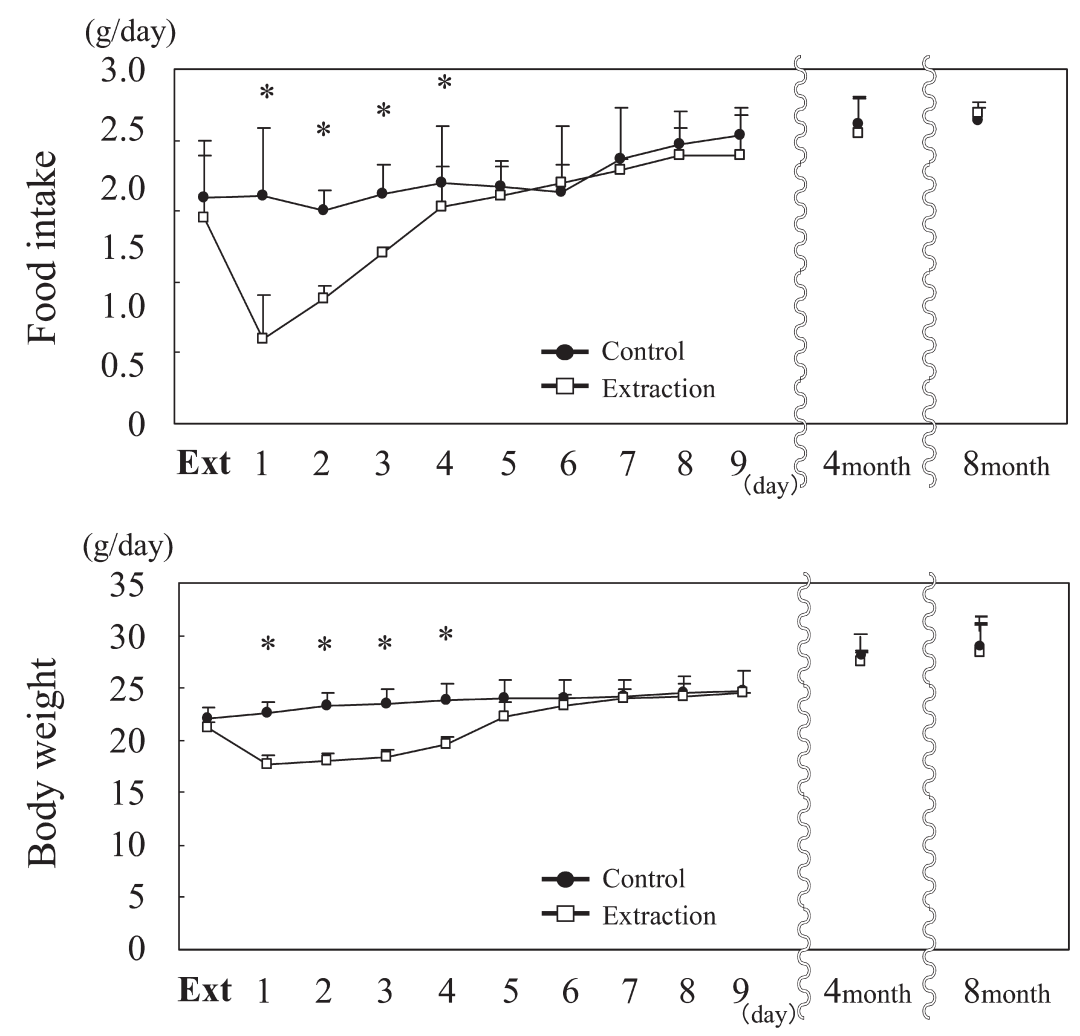

$*: P<0.05$

Fig. 1 Effects of the extraction condition on body weight and food intake

group were anesthetized with pentobarbital sodium $(40 \mathrm{mg} / \mathrm{kg})$ and perfused transcardially with $30 \mathrm{ml}$ saline at $37^{\circ} \mathrm{C}$, followed by $100 \mathrm{ml}$ neutral buffered formalin. The brain was carefully removed and postfixed in the same fixative overnight at $4^{\circ} \mathrm{C}$. Serial sections $(15 \mu \mathrm{m})$ were cut and mounted on glass slides, and stained with Cresyl Violet. Quantitative analysis of hippocampal pyramidal cells was performed as described previously ${ }^{18}$. Briefly, round, clear, medium, and large cells were counted in the left dorsal hippocampus (Bregma: $-2.46 \mathrm{~mm}$ using the atlas of Franklin and Paxinos ${ }^{19)}$ ). Ten sections per mouse were prepared. At 3 points in each of the CA1, CA3, and dentate gyrus (DG) regions of each section, the cells in a $100 \mu \mathrm{m} \times 100 \mu \mathrm{m}$ square area were counted, and the cell count per $\mathrm{mm}^{2}$ was calculated.

\section{Statistics}

The data were statistically processed by analysis of variance and, then, by Scheffe's or Tukey's multiple comparison procedure. A $P$-value of less than 0.05 was considered statistically significant.

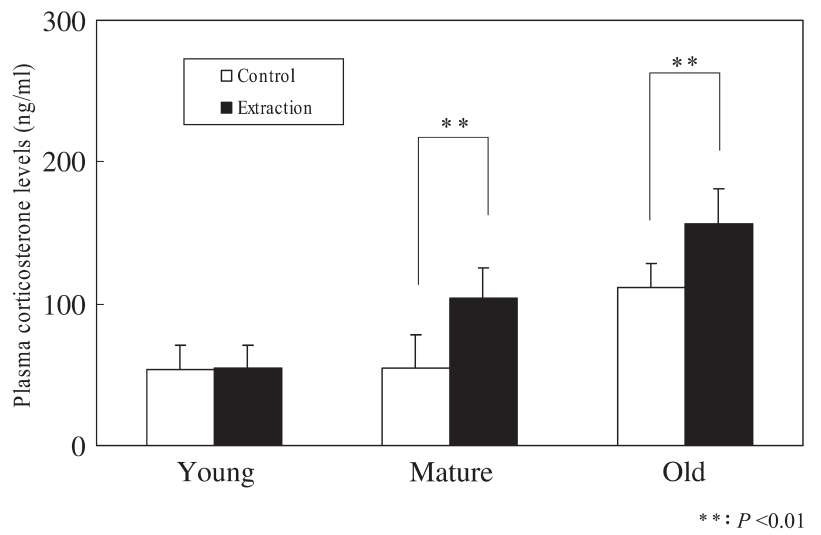

Fig. 2 Effects of the extraction condition on plasma corticosterone levels

\section{Results}

\section{Body weight and food intake}

The changes in body weight and food intake are shown in Fig. 1. For the first week after the operation, body weight and food intake decreased slightly in all of the molarless mice. After 1 week, however, 
(A)

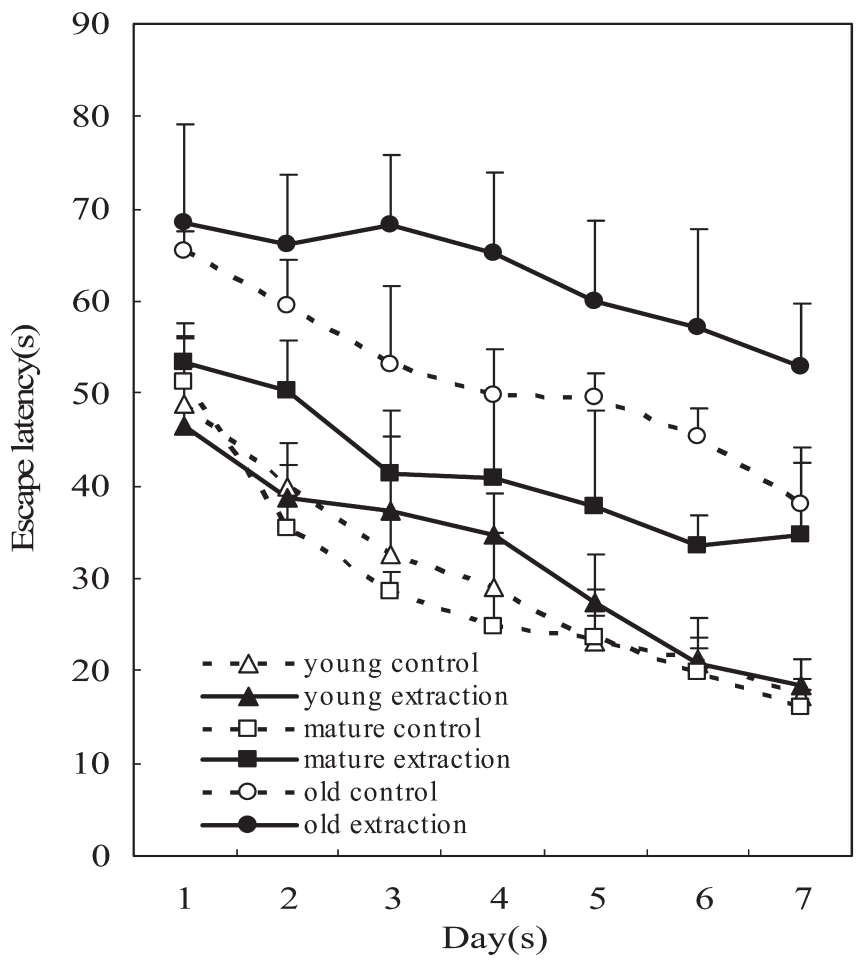

(B)

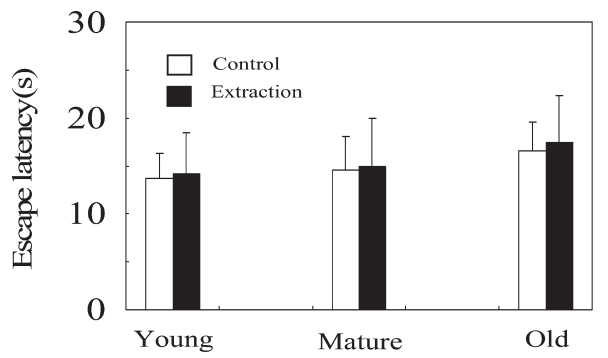

Fig. 3 (A) Spatial learning in the water maze test. The results are expressed as the mean score (mean $\pm \mathrm{SE}, \mathrm{n}=5$ for each group) of four trials per day.

(B) Visible probe test

these effects were completely restored and body weight and food intake were equivalent to those of control mice.

\section{Plasma corticosterone concentration}

The changes in plasma corticosterone concentration due to early tooth loss are shown in Fig. 2. The plasma corticosterone concentration in old mice or mature mice in the tooth extraction group was approximately $141 \%, 191 \%$ that in the age-matched controls, indicating a significant increase $[F(2,24)=$ $5.940646, P<0.01]$. In the young, on the other hand, there was no significant difference in the plasma corticosterone levels between the tooth extraction and control groups.

\section{Morris water maze test}

The results of the Morris water maze test for the tooth extraction and control groups are shown in Fig. 3. The time required to reach the platform decreased with repeated trials regardless of age or group $[F(144,6)=27.939, P<0.0001]$, and significantly increased with an increase in age $[F(144,2)$ $=23.057, P<0.0001]$. The decrease in the time to reach the platform was significantly smaller in the mature or old tooth extraction groups than in their age-matched controls $[F(6,144)=27.886, P<0.05]$, but there was no significant difference between the young tooth extraction and control groups. 


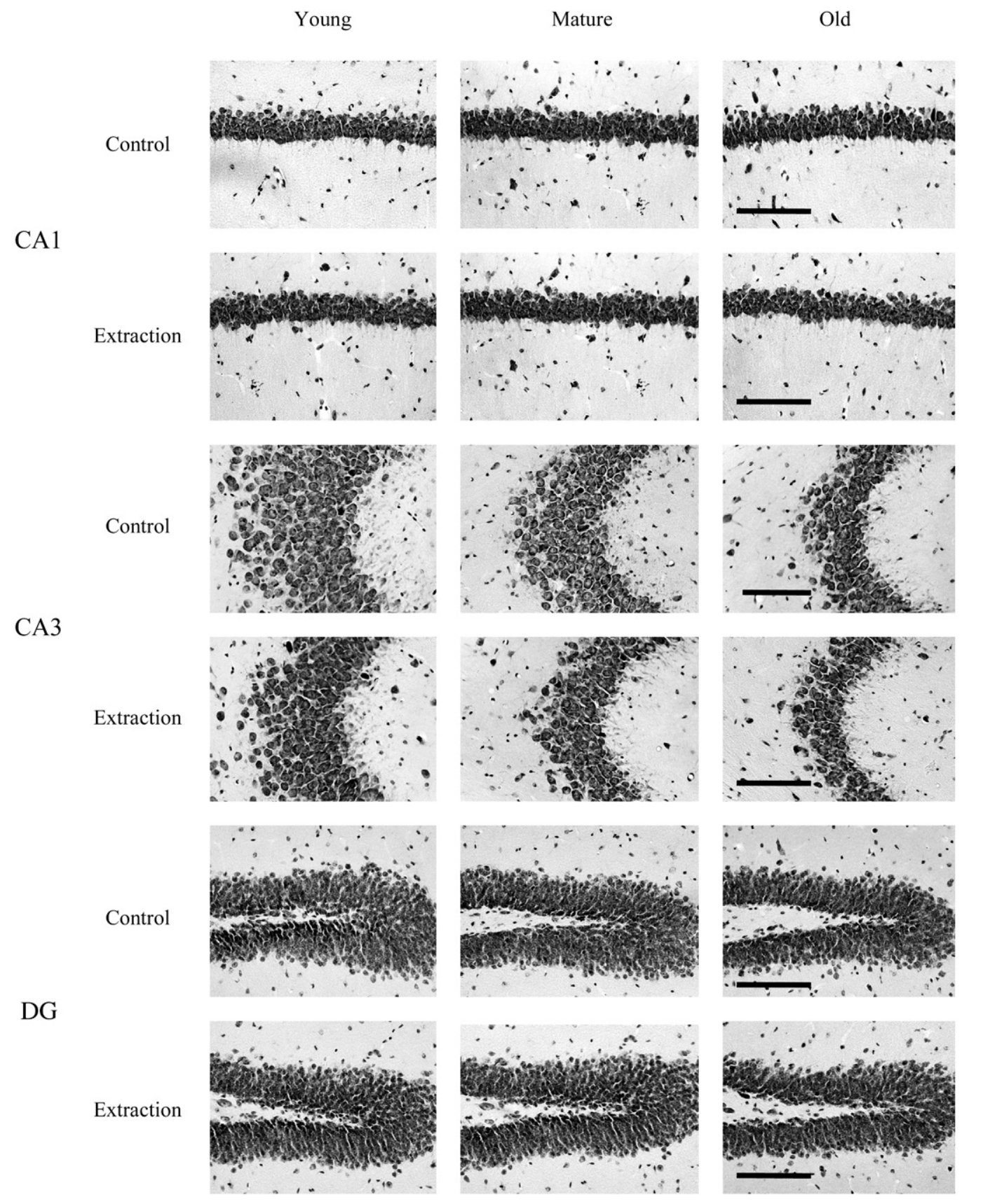

Fig. 4 Photomicrographs showing Nissl staining of hippocampal CA1, CA3 and DG subfield of control and extraction mice. Bars $200 \mu \mathrm{m}$.

\section{Hippocampal neuron number}

Nissl-stained pyramidal cells in CA1, CA3, and DG regions of the hippocampus are shown in Fig. 4. The results of the quantitative analysis of neurons in the three regions of the hippocampus are shown in Fig. 5. The number of neurons in the three regions decreased with age in both the tooth extraction and control groups [CA1: $F(2,294)=62.62458, P<$ 0.0001, CA3: $F(2,294)=15.69082, P<0.0001$, DG: $F(2,294)=82.20859, P<0.0001]$. Tukey's multiple comparisons, revealed that the number of neurons in the CA3 region was significantly lower in the mature and old tooth extraction groups than in the age-matched controls (mature, $85 \%$; old, $88 \%$ that of age-matched controls; $P<0.01$ ). In the CA1 and DG 

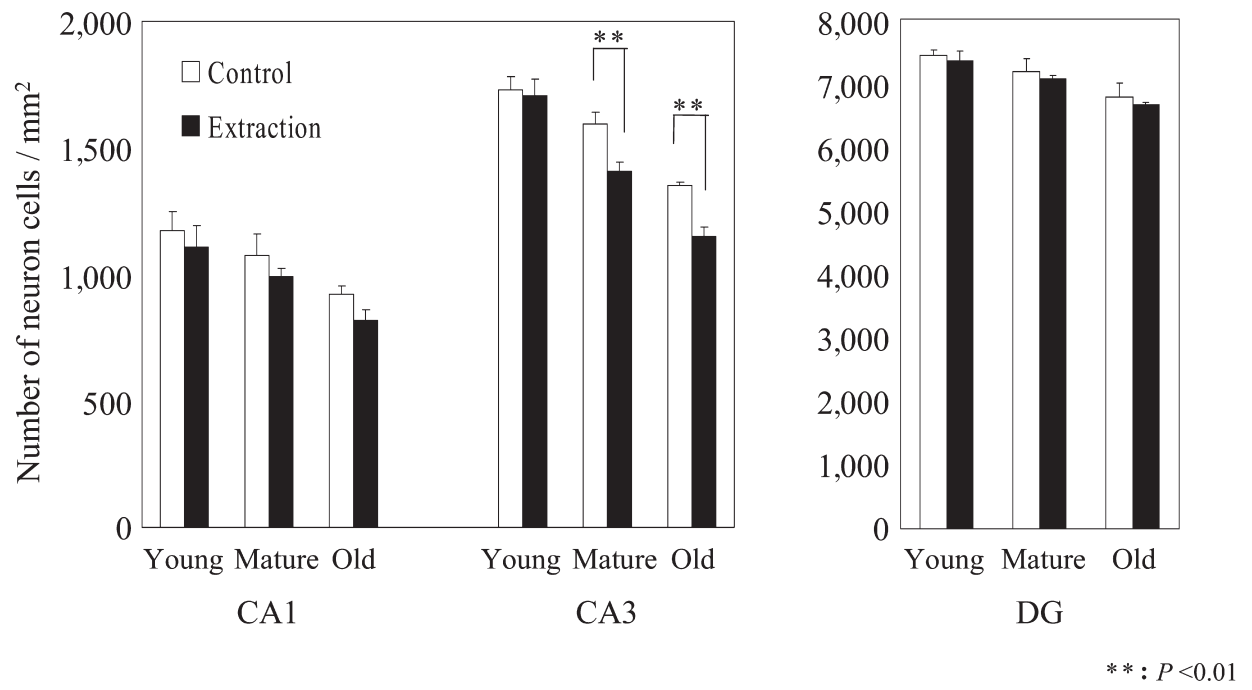

Fig. 5 Effects of the extraction condition on neuronal number in the hippocampal CA1, CA3 and DG subfield

regions, on the other hand, there was no significant difference in the number of neurons in the mature or old tooth extraction and control groups. In the young mice, there was no significant difference in the number of neurons in the three hippocampal regions between the tooth extraction and control groups.

\section{Discussion}

In the present study, we extracted only the upper molars because mice die when their incisors are extracted $^{5)}$ and there was no difference in the life span or degree of aging according to the site of tooth extraction.

In both the tooth extraction and control groups in the present study, the decrease in the time to reach the platform in the Morris water maze with repeated trials was slower with aging. This finding is consistent with previous reports that spatial memory declines with aging ${ }^{20,21)}$. The time needed to reach the platform did not differ between the young tooth extraction and control groups, but was significantly prolonged in the old tooth extraction group compared to their age-matched controls. Similar results are observed in bite-raised and tube-fed animals ${ }^{22-24)}$. Based on the findings of the present study, early tooth loss also accelerates the age-associated decline in spatial memory.

Typical age-associated changes in the hippocampus are a decline in spatial memory and neuronal death $^{21,25)}$. Because a decline in spatial memory was observed in the mature or old tooth extraction groups, we examined the effect of early tooth loss on the number of hippocampal neurons. The number of pyramidal cells was markedly reduced in the CA3 region in the mature or old tooth extraction groups compared with the age-matched control groups. The number of neurons in the CA1 and DG regions, however, did not significantly differ between the tooth extraction and control groups. In the young mice, there was no significant difference in the number of neurons in all three areas (CA1, CA3, and DG) of the hippocampus between the tooth extraction and control groups. These results suggest that early tooth loss accelerates both functional and organic age-associated changes.

The neurotoxicity of stress-related agents such as corticosterone and a decrease in signal input may cause neuronal death. Mice have an innate physiologic requirement to grind their teeth ${ }^{26}$. The inability of a mouse to grind their teeth due to tooth loss is considered to induce stress in the animals. Hagiwara et al. ${ }^{27)}$, Clark et al. ${ }^{28)}$, and Takeda ${ }^{29)}$ reported that impaired mastication due to occlusal interference induces sleep disorders, changes in autonomic activities, including neuroendocrine responses, and emotional stress. On the other hand, decreases in the incidence of gastric ulcer, which is a stress-related disorder induced by excessive mastication, decreases in ulcer size, and suppression of brain neurotransmitters have also been reported ${ }^{29)}$. In the body 
defense system, the hypothalamus-pituitary-adrenal cortex system acts as a mediator between the immune and endocrine systems, and the circulating concentration of cortisol, which is a hormone secreted from the adrenal cortex that controls defense responses, is considered an index of stress ${ }^{30)}$. Therefore, tooth extraction is considered to cause stress.

Because the declines in spatial memory observed in the mature or old tooth extraction groups closely resembled the functional and morphological changes of animals under chronic stress or long-term glucocorticoid administration $^{25,31)}$, we evaluated the changes in the plasma corticosterone concentration in the mice. The plasma corticosterone concentration was significantly elevated in the mature or old tooth extraction group compared with age-matched controls. In the young mice, however, the plasma corticosterone concentration in the tooth extraction groups was not significant different from that of the controls. In mature mice there is possibility to adapt to their tooth-extracted oral condition, but in old mice it is difficult to adapt. These results suggest that tooth loss acted as a chronic stressor in the mature or old SAMP8 mice.

Luine et al. ${ }^{25)}$ reported that 21-day restraint stress impairs spatial perception in rats and induced atrophy of the dendritic processes in the CA3 region of the hippocampus. Furthermore, Sapolsky et al. ${ }^{31)}$ demonstrated that the administration of corticosterone over 12 weeks induced pyramidal cell death in the CA3 region. Neuronal degeneration in the CA3 region is not observed in rats administered a glucocorticoid synthesis inhibitor, even under chronic stress $^{32}$. Indeed, Onozuka et al. $\left.{ }^{6}\right)$ reported that toothextracted mice administered metyrapone, a corticosterone synthesis inhibitor, did not differ from controls in the decline in spatial perception and hippocampal neuronal death. Based on these observations, an elevated plasma corticosterone concentration appears to be closely associated with a decrease in pyramidal cells.

Another cause of cell death is considered to be a decrease in stimulation of the central nervous system such as by reduced periodontal sensibility due to the loss of teeth. Tooth loss and loss of the periodontal membrane inhibit the periodontalmasseter reflex, with a consequent inability to increase the occlusal force ${ }^{33)}$, inability to bite with a sufficient force due to weak jaw-closing muscle activity resulting from masticatory muscle hypoplasia $^{34,35)}$, and weakening of the mastication force due to an insufficient number of motor neurons supplying the jaw-closing muscles ${ }^{36}$. These disorders may lead to a decrease in the mastication force and less stimulation of the central nervous system. Conversely, activities such as mastication are reported to increase temperature ${ }^{37)}$ and blood flow ${ }^{38)}$ over wide areas of the brain and to enhance the secretion of brain-gut hormones and cell activity ${ }^{8}$. Further, a decrease in the number of Fos-positive cells in the $\mathrm{CA} 3$ region in association with impaired performance in the Morris water maze has been reported in aged SAMP8 with early tooth loss. As soon as neurons receive input, the immediate early gene c-fos gene, is expressed, and Fos protein is produced ${ }^{12)}$. This protein is expressed in the hippocampus in association with learning activity ${ }^{39,40)}$. Therefore, the decrease in Fos protein production in aged mice with early tooth loss suggests that signal input to the hippocampus was decreased due to tooth loss. External information transmitted to the hippocampus is coded as it is transmitted to the $\mathrm{DG} \rightarrow \mathrm{CA} 3 \rightarrow \mathrm{CA} 1$ pathway, and transferred to the association areas to establish long-term memory ${ }^{41}$. Therefore, the loss of teeth may reduce information input into the association areas thereby impairing memory formation.

The effect of tooth extraction on neuron number was observed only in the CA3 region and not in the CA1 and DG regions. Glutamic acid, an excitatory neurotransmitter released from mossy fiber terminals projecting from DG to $\mathrm{CA} 3$, is reportedly involved in changes in the neurons in the CA3 region ${ }^{42)}$. Glucocorticoid promotes the release of glutamic acid. Increases in glucocorticoid levels and in the release of excitatory amino acids are speculated to act synergistically as neurotoxins to induce neuronal death in the CA3 region ${ }^{43}$.

Accelerated aging was observed in mature or old mice due to the early loss of teeth, but not in young mice. Because the plasma glucocorticoid levels generally increase with aging ${ }^{44)}$, the increase in glucocorticoid levels in mature or old mice is intensified by the stress of early tooth loss, glucocorticoid receptor mRNA and glucocorticoid receptors are down-regulated in the hippocampus, and not only are glucocorticoid receptors reduced, but neurons are also damaged by glucocorticoid. As a result, the negative feedback mechanism from the hippocampus to the hypothalamus is suppressed, and the elevated glucocorticoid level is considered to aggravate the damage to hippocampal neurons. In young mice, however, the glucocorticoid level is initially low, 
so that downregulation of glucocorticoid receptors or glucocorticoid receptors mRNA is less likely to occur, and negative feedback from the hippocampus to the hippocampal-pituitary-adrenal-axis functions normally to prevent an increase in glucocorticoid. This likely helps to prevent neuronal death in young mice, even under the stress of tooth loss.

Also, the effects of tooth extraction on the central nervous system may not appear over a short period. In studies of spatial memory ${ }^{45)}$, performance is improved with the number of trials 1 week after tooth extraction, and there is no difference between the tooth extraction and control groups. Performance is impaired in tooth extracted mice compared to controls 7 weeks after tooth extraction, indicating effects on brain function. Kubota et al. ${ }^{46)}$ reported that, in tree shrews and monkeys, the alveolar bone nerve degenerates after tooth extraction, but the infraorbital nerve takes longer to degenerate, and histologic effects of tooth extraction on the central nervous system are also considerably delayed. In addition, Kato et al. ${ }^{11)}$ reported that long-term tooth loss in rats impairs cholinergic neuron function, leading to a decline in learning and memory abilities. Watanabe et al. ${ }^{47)}$ reported that the experimental long-term administration of glucocorticoid induces not only a decline in spatial perception but also the degeneration and death of hippocampal neurons, and that hippocampal function becomes more impaired with increased exposure to glucocorticoid. In the present study, the effects of glucocorticoid administration were observed in the mature or old animals but not in young mice, and this is probably because of the prolonged stress after tooth extraction and because the glucocorticoid neurotoxicity became more evident with the increase in the exposure period and was not just a result of aging alone.

\section{Conclusion}

The effects of early tooth loss on hippocampal function were evaluated in senescence-accelerated mice. The plasma corticosterone concentration was increased in mature or old animals, indicating that tooth loss acted as a stressor. Spatial memory declined and the number of hippocampal neurons decreased in both mature or old animals, suggesting that hippocampal function is impaired by early tooth loss.

These results suggest that early tooth loss induces impairment of the hippocampal function.

\section{Acknowledgements}

This study was supported by a Grant-in-Aid for Scientific Research (No. 20592420) from the Ministry of Education, Science, Sports, and Culture in Japan.

\section{References}

1) Kondoh, K., Niino, M. and Shido, K.: A case-control study of Alzheimer's disease in Japan - significance of life-style. Dementia 5: 314-326, 1994. (in Japanese)

2) Okimoto, K., Ieiri, K., Matsuo, K. and Terada, Y.: Aging and mastication: The relationship between oral status and the progress of denentia at senile hospital. J Jpn Prosthodont Soc 35: 931-943, 1991. (in Japanese)

3) Marzooq, A.A., Yatabe, M. and Ai, M.: What types of occlusal factors play a role in temporomandibular disorders...? A literature review. J Med Dent Sci 46: 111-116, 1999.

4) Kubo, K., Yamada, Y., Iinuma, M., Kogaya, Y., Iwaku, F. and Tamura, Y.: Effect of masticatory dysfunction on the rate of aging and life span in senescenceaccelerated mice. J Gifu Dent Soc 33: 111-115, 2006.

5) Suzuki, Y., Iinuma, M., Yasui, S., Takata, M., Mineda, Y. and Tamura, Y.: Effects of tooth absence on the growth, aging span in SAMP1 mice. Jpn J Ped Dent 40: 103-113, 2002. (in Japanese)

6) Onozuka, M., Watanabe, K., Fujita, M., Tonosaki, K. and Saito, S.: Evidence for involvement of glucocorticoid response in the hippocampal changes in aged molarless SAMP8 mice. Behav Brain Res 131: 125-129, 2002.

7) Reul, J.M. and Kloet, E.R.: Two receptor systems for corticosterone in rat brain: microdistribution and differential occupation. Endo 117: 2505-2511, 1985.

8) Onozuka, M., Watanabe, K., Mirbod, S.M., Ozono, S., Nishiyama, K., Karasawa, N. and Nagatsu, I.: Reduced mastication stimulates impairment of spatial memory and degeneration of hippocampal neurons in aged SAMP8 mice. Brain Res 826: 148-153, 1999.

9) Watanabe, K., Tonosaki, K., Kawase, T., Karasawa, N., Nagatsu, I., Fujita, M. and Onozuka, M.: Evidence for involvement of dysfunctional teeth in the senile process in the hippocampus of SAMP8 mice. Exp Gerontol 36: 283-295, 2001.

10) Onozuka, M., Watanabe, K., Nagasaki, S., Jiang, Y., Ozono, S., Nishiyama, K., Kawase, T., Karasawa, N. and Nagatsu, I.: Impairment of spatial memory and changes in astroglial responsiveness following loss of molar teeth in aged SAMP8 mice. Behav Brain Res 108: 145-155, 2000.

11) Kato, T., Usami, T., Noda, Y., Hasegawa, M., Ueda, M. and Nabeshima, T.: The effect of the loss of molar teeth on spatial memory and acetylcholine release from the parietal cortex in aged rats. Behav Brain 
Res 83: 239-242, 1997.

12) Watanabe, K., Ozono, S., Nagasaki, S., Saito, S., Tonosaki, K., Fujita, M. and Onozuka, M.: The molarless condition in aged SAMP8 mice attenuates hippocampal Fos induction linked to water maze performance. Behav Brain Res 128: 19-25, 2002.

13) Takeda, T., Hosokawa, M., Takeshita, S., Irino, M., Higuchi, K., Matsushita, T., Tomita, Y., Yasuhira, K., Hamamoto, H., Shimizu, K., Ishii, M. and Yamamuro, T.: A new murine model of accelerated senescence. Mech Aging Dev 17: 183-194, 1981.

14) Takeda, T., Hosokawa, M., Higuchi, K., Hosono, M., Akiguchi, I. and Katoh, H.: A novel murine model of aging, Senescence-Accelerated Mouse (SAM). Arch Gerontol Geriatr 19: 185-192, 1994.

15) Aguilera, G.: Regulation of pituitary ACTH secretion during chronic stress. Front Neuroendocrinol 15: 321-350, 1994.

16) Morris, R.G.M.: Development of a water-maze procedure for studying spatial learning in that rat. J Neurosci Methods 11: 47-60, 2007.

17) Skelton, R.W. and McNamara, R.K.: Bilateral knife cuts to the perforant path disrupt spatial learning in the Morris water maze. Hippocampus 2: 73-80, 1992.

18) Kato, D., Hozumi, E., Murakami, H., Yokoyama, T., Ito, Y., Maeda, H. and Kameyama, Y.: The effect of age-related changes and loss of molar tooth on hippocampal pyramidal cells in senescence-accelerated mouse (SAM) - Morphological study - . J J Gerodont 16: 327-335, 2002. (in Japanese)

19) Franklin, K.B. and Paxinons, K.B.J.: The Mouse Brain in Stereotaxic Coordinates. Academic Press, New York, 1996, p. 51.

20) Drapeau, E., Montaron, M.F., Aquerre, S. and Abrous, D.N.: Leaning-induced survival of new neurons depends on the cognitive status of aged rats. $J$ Neurosci 22: 6037-6044, 2007.

21) Morrison, J.H. and Hof, P.R.: Life and death of neurons in the aging brain. Science 278: 412-419, 1997.

22) Kubo, K., Yamada, Y., Iinuma, M., Iwaku, F., Tamura, Y., Watanabe, K., Nakamura, H. and Onozuka, M.: Occlusal disharmony induces spatial memory impairment and hippocampal degeneration via stress in SAMP8 mice. Neurosci Lett 414: 188-191, 2007.

23) Nishida, Y., Iinuma, M., Tamura, Y., Kubo, K. and Iwaku, F.: Effect of tube feeding on hippocampaldependent memory in SAMP1 mice. Ped Dent J 17: 47-52, 2007.

24) Nishida, Y., Inagaki, Y., Iinuma, M., Tamura, Y., Kubo, K. and Iwaku, F.: Influence of tube feeding on spatial memory and the number of hippocampus pyramidal cells in SAMP1 mice. J Gifu Dent Soc 33: 185-190, 2007.

25) Luine, V., Villegas, M., Martinez, C. and McEwen, B.S.: Repeated stress causes reversible impairments of spatial memory performance. Brain Res 639: 167-170, 1994.

26) Matsumura, A.: Daijisen. Shogakukan, 1995, p. 838. (in Japanese)

27) Hagiwara, A. and Kobayashi, Y.: Studies of bruxism during sleep - Analyses of electromyogram, electroencephalogram, electro-oculogram, electrocardiogram, respirogram, clinical findings, psychoendocrine responses taken before, during, and after horizontal experimental occlusal interference-. Shigaku 73: 946-1019, 1985. (in Japanese)

28) Clark, G.T., Rugh, J.D. and Handelman, S.L.: Nocturnal masseter muscle activity and urinary catecholamine levels in bruxers. J Dent Res 59: 1571-1576, 1980.

29) Takeda, Y.: Studies of bruxism during sleep - Comparisons of electromyogram, electroencephalogram, electro-oculogram, electrocardiogram, respirogram, psychoendocrine responses, and clinical findings taken before, during, and after experimental occlusal interference -. Shigaku 71: 276-337, 1983. (in Japanese)

30) Sato, S. and Miyachi, Y.: Steroid hormones and sports. Clinical Endocrinol 40: 45-50, 1992. (in Japanese)

31) Sapolsky, R.M., Krey, L.C. and McEwen, B.S.: The neuroendocrinology of stress and aging: the glucocorticoid cascade hypothesis. Endocrine Rev 7: 284-301, 1986.

32) McEwen, B.S.: Corticosteroids and hippocampal plasticity. Ann N Y Acad Sci 746: 134-142, 1994.

33) Lavigne, G., Kim, J.S., Valiquette, C. and Lund, J.P.: Evidence that periodontal pressoreceptors provide positive feedback to jaw closing muscles during mastication. J Neurophysiol 58: 342-358, 1987.

34) Yamamura, C., Kosugi, S., Ono, K. and Shimada, K.: Patterns of jaw reflexes induced by incisal and molar pressure stimulation in relation to background levels of jaw-clenching force in humans. Jpn J Physiol 43: 87-102, 1993.

35) Yamamura, C. and Shimada, K.: Differential controls of small and large motor unit activity in the masseter muscle with incisal stimulation in humans. Brain Res 632: 339-341, 1993.

36) Suemune, S., Kawata, T. and Maeda, N.: Reduction of masticatory motoneurons in the trigeminal motor nucleus of the toothless (op/op) mouse. Biomedical Res 15: 45-49, 1994.

37) Rampone, A.J. and Shirasu, M.E.: Temperature changes in the rat in response to feeding. Science 144: 317-319, 1964.

38) Momose, T., Nisikawa, J., Watanabe, T., Sasaki, Y., Senda, M., Kubota, K., Sato, Y., Funakoshi, M. and Minakuchi, S.: Effect of mastication on regional cerebral blood flow in humans examined by positronemission tomography with ${ }^{15} \mathrm{O}$-labelled water and magnetic resonance imaging. Arch Oral Biol 42: 57-61, 1997.

39) Anokhin, K.V., Mileusnic, R., Shamakina, I.Y. and Rose, S.P.: Effects of early experience on c-fos gene expression in the chick forebrain. Brain Res 544: 101-107, 1991.

40) Hess, U.S., Lynch, G. and Gall, C.M.: Changes in c-fos mRNA expression in rat brain during odor 
discrimination learning. Differential involvement of hippocampal subfields CA1 and CA3. J Neurosci 15: 4786-4795, 1995.

41) Olton, D.S., Becker, J.T. and Handelmann, G.E.: Hippocampus space and memory. Behav Brain Res 2: 313-365, 1979.

42) Sapolsky, R.M., Uno, H., Rebert, C. and Finch, C.: Hippocampal damage associated with prolonged glucocorticoid exposure in primates. J Neurosci 10: 2897-2902, 1990.

43) Sapolsky, R.M.: Glucocorticoid, hippocampal damage and the glutamatergic synapse. Prog Brain Res 86: 13-23, 1990.

44) Endo, Y.: Stress and glucocorticoid clin. Neurosci
21: 1022-1024, 2003. (in Japanese)

45) Chiba, A.: Effects of molar tooth loss on central nervous system with a behavioral and histological study in mice. J Jpn Prosthodont Soc 43: 299-311, 1999. (in Japanese)

46) Kubota, K., Nagae, K., Shibanai, S., Hosaka, K., Iseki, H., Odagiri, N., Lee, M.S., Chang, C.M., Ohkubo, K., Narita, N. and Sonoda, Y.: Degenerative changes of primary neurons following tooth extraction. Anat Anz Jena 166: 133-139, 1988.

47) Watanabe, Y., Gould, E. and McEwen, B.S.: Stress induces atrophy of apical dendrites of hippocampal CA3 pyramidal neurons. Brain Res 588: 341-345, 1992. 